\title{
Prognostic Significance of Red Cell Distribution Width in Idiopathic Pulmonary Fibrosis and Combined Pulmonary Fibrosis Emphysema
}

\author{
Aslıhan Gürün Kaya ${ }^{a}$ Berna Akıncı Özyürek ${ }^{b}$ Tuğçe Şahin Özdemirel ${ }^{b}$ \\ Miraç Öz ${ }^{a}$ Yurdanur Erdoğan ${ }^{b}$

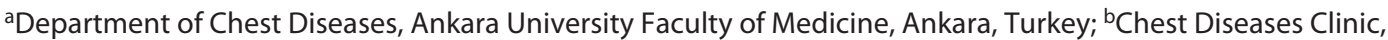 \\ Ataturk Chest Diseases and Chest Surgery Education and Research Hospital, Ankara, Turkey
}

\section{Highlights of the Study}

- Red cell distribution width (RDW) is a prognostic indicator for several diseases.

- This study showed that RDW is negatively correlated with carbon monoxide diffusion capacity, partial arterial oxygen pressure, and six-minute walking distance and is positively correlated with systolic pulmonary arterial pressure.

- RDW is an independent risk factor for mortality in idiopathic fibrosis and combined pulmonary fibrosis emphysema.

\section{Keywords}

Red cell distribution width · Idiopathic pulmonary fibrosis . Combined pulmonary fibrosis emphysema

\begin{abstract}
Objective: The red cell distribution width (RDW) is an inexpensive, readily available prognostic indicator of several diseases. RDW has been assessed as a prognostic biomarker in patients with idiopathic pulmonary fibrosis (IPF) in only one study; furthermore, the relationship between the RDW and combined pulmonary fibrosis emphysema (CPFE) has yet to be reported. Subjects and Methods: This single-center study was conducted between January 2015 and December 2018 in the Atatürk Chest Diseases and Chest Surgery Education and Research Hospital. Baseline characteristics, laboratory results, and survival status of patients were recorded. $\boldsymbol{R} \boldsymbol{e}$ sults: The RDW value was significantly higher in the CPFE
\end{abstract}

karger@karger.com www.karger.com/mpp

Karger $\stackrel{\text { ' }}{5}$

GOPEN ACCESS
(C) 2020 The Author(s)

Published by S. Karger AG, Basel

This is an Open Access article licensed under the Creative Commons Attribution-NonCommercial-4.0 International License (CC BY-NC) (http://www.karger.com/Services/OpenAccessLicense), applicable to the online version of the article only. Usage and distribution for commercial purposes requires written permission. group than in the IPF group (median [IQR 25-75]; 16.8 [15.5$19]$ vs. 15.3 [13.7-16.8], $p=0.028$ ). High RDW values were correlated with carbon monoxide diffusion capacity (DLCO) $(r:-0.653 p=0.001), 6$-minute walking test (6MWT) distance $(r:-0.361 p=0.017)$, arterial partial oxygen pressure $\left(\mathrm{PaO}_{2}\right)$ $(r:-0.692 p<0.001)$, and systolic pulmonary arterial pressure (SPAP) ( $r: 0.349 p=0.022)$ in patients with fibrotic lung disease. The RDW value was significantly higher in the exitus group than in the survivors (median [IQR 25-75]; 18.4 [15.4$19]$ vs. 15.2 [13.5-17.2], $p=0.016)$. A univariate Cox regression analysis identified DLCO, SPAP, $\mathrm{PaO}_{2}$, and RDW as potential covariates of mortality. In a multivariate analysis, the DLCO (HR 1.21, 95\% Cl 1.11-1.47, $p=0.012$ ) and RDW level (HR 1.65, 95\% Cl 1.09-2.47, $p=0.023$ ) remained independent predictors of mortality. Conclusion: High RDW values appear to be a simple prognostic factor in patients with IPF or CPFE.

(c) 2020 The Author(s)

Published by S. Karger AG, Basel 


\section{Introduction}

The red cell distribution width (RDW) test is an inexpensive and available measure of a parameter that is routinely reported as a component of complete blood count in differential diagnoses of anemia. It reflects the variability in size of erythrocytes in peripheral blood and the ineffective erythropoiesis of bone marrow [1]. In recent years, RDW has been shown to be a prognostic indicator for several diseases [2]. Elevated RDW values have been found in adults with a wide variety of heart diseases, including stable coronary disease, acute myocardial infarction, pulmonary hypertension $(\mathrm{PH})$, and pulmonary embolism $[3,4]$, and RDW has been found to be associated with increased risk of mortality in the general population [5].

Idiopathic pulmonary fibrosis (IPF) is a chronic, progressive parenchymal lung disease that has been associated with a typical radiologic pattern (subpleural and basal predominance, reticulations, honeycombing with or without bronchiectasis, and no atypical images) and histopathologic pattern (marked fibrosis with architectural distortion, subpleural, patchy involvement of the lung, fibroblast foci, and absence of inconsistent features) [6]. Combined pulmonary fibrosis and emphysema (CPFE) is characterized by lower lobe fibrosis, upper lobe emphysema, and abnormalities in gas exchange. Although CPFE and IPF have similar features at first glance, they have different outcomes and pulmonary functional test results $[7$, 8]. The clinical courses of the 2 diseases range from a slowly progressive decline lasting for several years to a rapid deterioration and death in a matter of months [9].

RDW has been investigated as a prognostic biomarker in patients with IPF in only one study to date [10], while the relationship between RDW and CPFE has not been reported. In the present study, we test the usefulness of RDW in the prognosis of CPFE and IPF.

\section{Subject and Methods}

\section{Study Design}

This single-center ambidirectional study was conducted in the Atatürk Chest Diseases and Chest Surgery Education and Research Hospital. The study patients were enrolled between January 2015 and June 2017 and subsequently followed up until December 2018 to screen for mortality. To be defined as having CPFE, there had to be evidence of emphysema or bullous disease and lower lobe predominance pulmonary fibrosis on a computer tomography (CT) scan (conventional or high-resolution) report or a lung pathology report. Emphysema was defined as the presence of welldemarcated areas of decreased attenuation identified in comparison with a normal lung and marginated by a very thin wall $(<1$ $\mathrm{mm}$ ) or no wall, and/or multiple bullae $(>1 \mathrm{~cm})$ with upper zone predominance on a chest CT [8]. IPF is defined as the presence of a UIP pattern in a pathological specimen and/or by thorax CT in patients with no evidence of underlying collagen vascular diseases identified from clinical manifestations or laboratory tests.

Patients with systolic heart failure; history of blood diseases, including all kinds of anemia and hematopoietic abnormalities related to increasing RDW; and missing data were excluded from the study. This study protocol was approved by the human research Ethics Committee of our hospital.

\section{Data Collection}

Data were collected through a search of the hospital's digital information system. Demographic characteristics (including the patients' age, sex, and BMI), laboratory parameters at admission (including complete blood count, liver and renal functional test and arterial blood gas test), 6MWT results, and pulmonary functional data were recorded.

\section{Statistics}

Statistical analyses were carried out using the SPSS version 20 software package. The variables were investigated using visual (histograms and probability plots) and analytical (KolmogorovSmirnov/Shapiro-Wilk's test) methods to determine the normality of distribution. Normally distributed variables were presented as mean and SD, while non-normally distributed variables were presented as median and interquartile range (IQR). A Student's $t$ test and a Mann-Whitney U test were used for the between-group comparison. The $\chi^{2}$ test or Fisher's exact test was used to compare categorical variables. The correlation coefficients and their significance were calculated using the Pearson's or Spearman's tests. The RDW and clinical/laboratory parameters for mortality were assessed with Cox regression analyses. A $p$ value of $<0.05$ was considered statistically significant.

\section{Results}

During the study period, 30 patients were diagnosed with IPF, and 34 were diagnosed with CPFE. After 21 patients were excluded from the study, a total of 43 patients (22 with IPF and 21 with CPFE) were evaluated (Fig. 1), of whom 32 (74.4\%) were male. The baseline functional parameters at the time of diagnosis of the 43 patients are presented in Table 1. The RDW values of study patients ranged from 12.9 to $24 \%$, and the median value for the group was $15.2 \%$. Univariate analyses revealed the RDW value to be significantly higher in the CPFE group when compared to the IPF group (median [IQR 25-75]; 16.8 [15.5-19] vs. 15.3 [13.7-16.8], $p=0.028)$. Thirty-seven patients $(86 \%)$ had a history of smoking, with no significant difference noted between the CPFE and IPF groups ( 86.6 vs. $85.8 \%, p=0.754$ ) in this regard.

A correlation analysis of the entire patient group demonstrated that RDW was negatively correlated with the carbon monoxide diffusion capacity (DLCO), arterial 
Fig. 1. Study flowchart diagram. IPF, idiopathic pulmonary fibrosis; CPFE, combined pulmonary fibrosis emphysema.

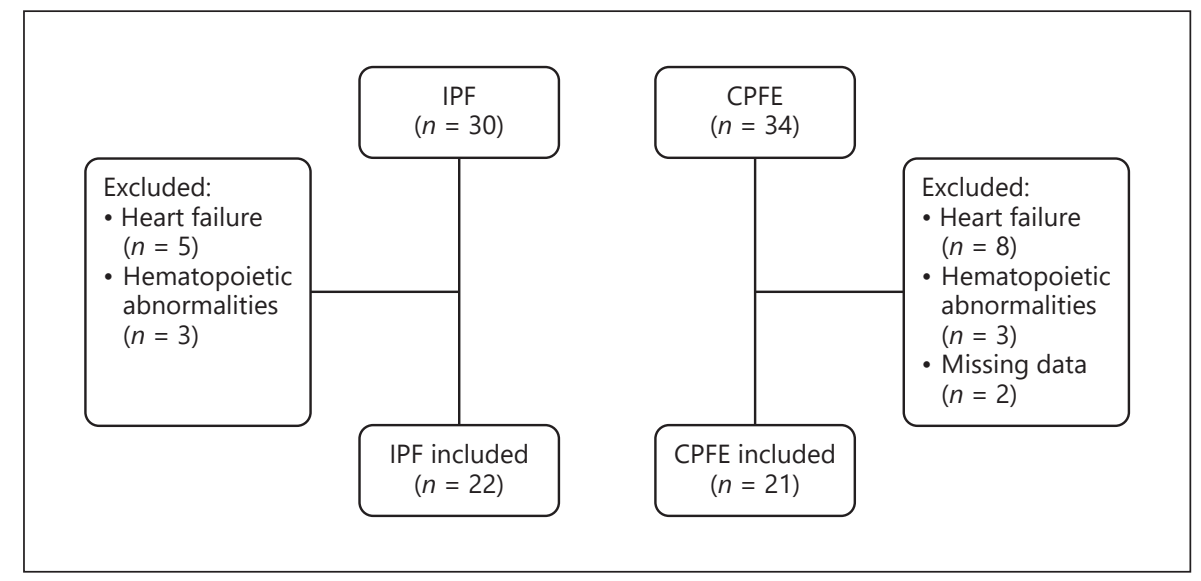

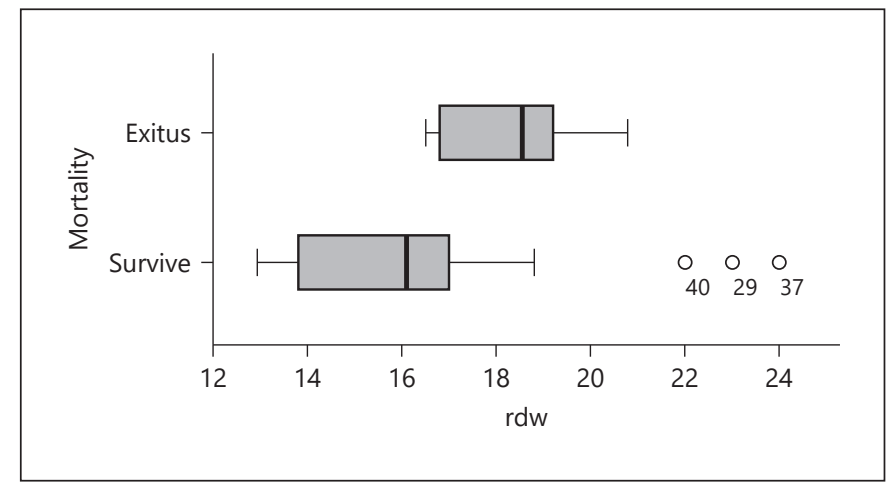

Fig. 2. Comparison of RDW values between exitus and survivor patients. RDW, red cell distribution width.

Table 1. The baseline functional parameters at the time of diagnosis

\begin{tabular}{lccc}
\hline & IPF (22) & CPFE (21) & $p$ value \\
\hline Age & $63.86 \pm 10.05$ & $60.57 \pm 11.29$ & 0.31 \\
FEV $_{1}, \%$ & $71.50[64.75-77.25]$ & $76[66.5-93.5]$ & 0.19 \\
$\mathrm{FVC}^{\circ} \%$ & $58.50[54.25-66.5]$ & $80[75.0-92.0]$ & $<\mathbf{0 . 0 0 1}$ \\
$\mathrm{FEV}_{1} / \mathrm{FVC}$ & $88[83.0-91.5]$ & $76[70-83.5]$ & $<\mathbf{0 . 0 0 1}$ \\
$\mathrm{TLC}, \%$ & $62[57.75-66.25]$ & $79[71.5-85.0]$ & $<\mathbf{0 . 0 0 1}$ \\
$\mathrm{RV}, \%$ & $82[69.75-87.25]$ & $104[97-117.5]$ & $<\mathbf{0 . 0 0 1}$ \\
$\mathrm{DLCO}, \%$ & $55.5[45.5-60.25]$ & $56[47.5-60.5]$ & 0.87 \\
6MWT & $410[290-430]$ & $370[325-447]$ & 0.81 \\
$\mathrm{SPAP}$ & $35[30-40]$ & $35[27.5-42.5]$ & 0.53 \\
$\mathrm{PaO}_{2}$ & $53.17 \pm 6.71$ & $52.07 \pm 5.04$ & 0.54 \\
\hline
\end{tabular}

$\mathrm{FEV}_{1}$, forced expiratory volume in $1 \mathrm{~s}$; FVC, forced vital capacity; TLC, total lung capacity; RV, residual volume; DLCO, carbon monoxide diffusing capacity; 6MWT, 6-min walking test distance; SPAP, systolic pulmonary arterial pressure; $\mathrm{PaO}_{2}$, partial oxygen pressure; IPF, idiopathic pulmonary fibrosis; CPFE, combined pulmonary fibrosis emphysema. Bold values denote statistical significance at the $p<0.05$ level. partial oxygen pressure $\left(\mathrm{PaO}_{2}\right)$, and 6MWT. Furthermore, a positive correlation was noted between RDW and systolic pulmonary arterial pressure (SPAP), with similar results observed in a subgroup analysis of the IPF and CPFE groups. RDW was not correlated with age, BMI, and forced vital capacity (FVC) or total lung capacity (TLC) in this study group Table 2.

Mortality was observed in 6 patients (14\%) at the end of the study; there were no significant differences in the mortality rates of the 2 groups IPF and CPFE (18.2 vs. 9.5\%, $p=0.66)$. The RDW value was significantly higher in the exitus group than in the survivors (median [IQR 25-75]; 18.4 [15.4-19] vs. 15.2 [13.5-17.2], $p=0.016$ ) (Fig. 2).

In order to determine the potential effect of the clinical and laboratory parameters on mortality, a univariate Cox regression analysis was employed, and it was found that RDW, DLCO, SPAP, and $\mathrm{PaO}_{2}$ were significantly associated with mortality (Table 3 ). Then, a Cox regression analysis was performed using the covariates that showed significance in the univariate analysis. DLCO (HR 1.21, 95\% CI 1.11-1.47, $p=0.012$ ) and RDW levels (HR 1.65, $95 \%$ CI $1.09-2.47, p=0.023$ ) were found to be independent predictors of mortality.

\section{Discussion}

FVC, TLC, DLCO, 6MWT, $\mathrm{PaO}_{2}$, and SPAP are physiologic parameters that are used for the assessment of disease severity in interstitial lung diseases $[11,12]$. Elevated levels of RDW have been reported to be related to cardiovascular diseases [13], malignancies [14, 15], PH [16], and pulmonary thromboembolism [4]. In the present study, we found high RDW values to be correlated with DLCO, 
Table 2. Correlation analyses of RDW levels and various clinical and laboratory parameters of study patients

\begin{tabular}{|c|c|c|c|c|c|c|}
\hline & \multicolumn{6}{|c|}{ RDW level } \\
\hline & \multicolumn{2}{|c|}{ IPF (22) } & \multicolumn{2}{|c|}{ CPFE (21) } & \multicolumn{2}{|c|}{ all groups (43) } \\
\hline & $r$ & $p$ value & $r$ & $p$ value & $r$ & $p$ value \\
\hline Age & 0.075 & 0.225 & 0.104 & 0.092 & 0.070 & 0.254 \\
\hline BMI & 0.032 & 0.602 & 0.025 & 0.688 & 0.075 & 0.224 \\
\hline FVC & -0.574 & 0.076 & -0.683 & 0.096 & -0.688 & 0.123 \\
\hline TLC & -0.365 & 0.165 & -0.415 & 0.246 & -0.322 & 0.607 \\
\hline DLCO & -0.605 & 0.002 & -0.686 & 0.006 & -0.653 & 0.001 \\
\hline 6MWT & -0.348 & 0.042 & -0.468 & 0.058 & -0.361 & 0.017 \\
\hline SPAP & 0.482 & 0.001 & 0.543 & 0.013 & 0.349 & 0.022 \\
\hline $\mathrm{PaO}_{2}$ & -0.760 & $<0.001$ & -0.610 & 0.002 & -0.692 & $<0.001$ \\
\hline
\end{tabular}

FVC, forced vital capacity; TLC, total lung capacity; DLCO, carbon monoxide diffusing capacity; 6MWT, 6-minute walking test distance; SPAP, systolic pulmonary arterial pressure; $\mathrm{PaO}_{2}$, partial oxygen pressure; IPF, idiopathic pulmonary fibrosis; CPFE, combined pulmonary fibrosis emphysema; RDW, red cell distribution width. Bold values denote statistical significance at the $p<0.05$ level.

Table 3. Univariate regression analysis of factors with increased mortality

\begin{tabular}{lrlll}
\hline & \multicolumn{1}{l}{$B$} & Sig & $\begin{array}{l}\text { Exp } \\
(B)\end{array}$ & $\begin{array}{l}\text { 95\% CI for } \\
\operatorname{Exp}(B)\end{array}$ \\
\hline Age & 0.046 & 0.126 & 0.954 & $0.811-1.112$ \\
Male gender & 0.002 & 0.870 & 1.003 & $0.968-1.039$ \\
BMI & 0.206 & 0.726 & 1.228 & $0.962-1.559$ \\
FVC & -0.038 & 0.092 & 0.963 & $0.890-1.042$ \\
TLC & -0.158 & 0.525 & 1.176 & $0.786-1.805$ \\
DLCO & -0.056 & $\mathbf{0 . 0 0 7}$ & 1.438 & $1.045-1.736$ \\
6MWT & -0.011 & 0.110 & 1.011 & $0.995-1.027$ \\
SPAP & 0.062 & $\mathbf{0 . 0 3 6}$ & 1.168 & $1.087-1.452$ \\
$\mathrm{PaO}_{2}$ & -0.826 & $\mathbf{0 . 0 4 2}$ & 1.662 & $1.334-2.406$ \\
$\mathrm{RDW}$ & 0.802 & $\mathbf{0 . 0 2 8}$ & 1.794 & $1.124-2.306$ \\
\hline
\end{tabular}

$B$, regression coefficient; $\operatorname{Exp}(B)$, hazard ratio; $\mathrm{CI}$, confidence interval; FVC, forced vital capacity; TLC, total lung capacity; DLCO, carbon monoxide diffusing capacity; 6MWT, 6-minute walking test distance; SPAP, systolic pulmonary arterial pressure; $\mathrm{PaO}_{2}$, partial oxygen pressure; RDW, red cell distribution width. Bold values denote statistical significance at the $p<0.05$ level.

6MWT distance, $\mathrm{PaO}_{2}$, and SPAP in patients with fibrotic lung disease Table 4.

Most reported cases of CPFE share similar characteristics, including relatively preserved spirometric values, decreased DLCO, and PH, and DLCO values have been noted to be lower in the CPFE patients than in the IPF patients $[7,17]$. Similarly, in the present study, patients with $\mathrm{CPFE}$ recorded better spirometric values, which can be attributed in part to emphysema-related hyperinflation
Table 4. Cox proportional-hazards regression to identify factors associated with increased mortality

\begin{tabular}{lrlll}
\hline & \multicolumn{1}{l}{$B$} & Sig & HR & $\begin{array}{l}\text { 95\% CI for } \\
\operatorname{Exp}(B)\end{array}$ \\
\hline Age & 0.046 & 0.545 & 0.954 & $0.811-1.112$ \\
FVC & -0.086 & 0.345 & 0.863 & $0.798-1.342$ \\
DLCO & -0.018 & $\mathbf{0 . 0 1 2}$ & 1.218 & $1.115-1.473$ \\
6MWT & -0.087 & 0.362 & 1.136 & $0.892-1.427$ \\
SPAP & 0.018 & 0.234 & 1.018 & $0.989-1.050$ \\
$\mathrm{PaO}_{2}$ & -0.523 & 0.078 & 1.842 & $0,912-2.419$ \\
$\mathrm{RDW}$ & 0.906 & $\mathbf{0 . 0 2 3}$ & 1.658 & $1.096-2.478$ \\
\hline
\end{tabular}

$B$, regression coefficient; $\operatorname{Exp}(B)$, hazard ratio; CI, confidence interval; FVC, forced vital capacity; DLCO, carbon monoxide diffusing capacity; 6MWT, 6-minute walking test; SPAP, systolic pulmonary arterial pressure; $\mathrm{PaO}_{2}$, partial oxygen pressure; RDW, red cell distribution width. Bold values denote statistical significance at the $p<0.05$ level.

[18]. Fibrosis and emphysema have cumulative effects on impaired gas exchange, linked to reduced vascular surface area and pulmonary capillary blood volume plus alveolar membrane thickening [7]. $\mathrm{PH}$ appears to be more frequent and more severe in patients with CPFE than in those with IPF. Furthermore, $\mathrm{PaO}_{2}$ and DLCO have been associated with elevated pulmonary arterial pressure $[19,20]$. In our study population, the $\mathrm{PaO}_{2}$, DLCO, and SPAP values did not differ between the IPF and CPFE groups, although these findings may be related to the lack of radiologic fibrosis and emphysema grading of the patients. 
Higher RDW values have been linked to worse prognoses in some pulmonary diseases, such as pulmonary embolism, chronic obstructive pulmonary disease (COPD), pneumonia, and respiratory failure $[4,21]$. Nathan et al. [10] identified a relationship between RDW, DLCO, and SPAP values and the survival rate of patients with IPF. The relationship between RDW and CPFE has yet to be reported.

We found RDW was found to be well correlated with $\mathrm{PaO}_{2}$ levels. Elevated RDW levels can be associated with hypoxemia. A decrease in $\mathrm{PaO}_{2}$ stimulates the release of erythropoietin (EPO), which brings about a change in $\mathrm{RBC}$ size distribution. Moreover, chronic inflammation leads to changes in the erythrocyte metabolism, in particular erythropoiesis and erythrocyte half-life [3, 22]. Although no significant difference in $\mathrm{PaO}_{2}$ was found between the IPF and CPFE groups, RDW values were higher in patients with CPFE than those with IPF. The onset of hypoxic disease adds to the patient's pre-existing condition and comorbid disease [22]. We believe that similar levels of $\mathrm{PaO}_{2}$ in the patient groups can be attributed to the patients' previous hypoxemic burden.

We observed a positive correlation between SPAP and RDW. RDW has been shown to be a predictor of outcomes in patients with idiopathic pulmonary arterial hypertension [23]. Alattar et al. [24] reported a positive correlation between RDW and SPAP in patients with heart failure with diastolic dysfunction. Hypoxia may trigger pulmonary arterial hypertension through vasoconstriction and structural vascular remodeling, such as smooth muscle hypertrophy and hyperplasia, in addition to collagen and elastin deposition. Also, a known effect of hypoxia-induced remodeling is the muscularization of distal lung arterioles; endothelial dysfunction in fibrotic lung disease may also elevate pulmonary arterial pressure [25]. RDW has been found to be associated with endothelial dysfunction in earlier studies [26, 27].

We found RDW to be negatively correlated with DLCO and 6MWT distances. Previous studies have shown DLCO levels to be lower in patients with increased RDW values than in those with normal RDW values in IPF patients [10]. Another study identified a negative correlation between RDW values and DLCO levels in patients with systemic sclerosis [28]. In addition, elevated RDW values have been found in previous studies to be associated with decreased 6MWT distance in patients with COPD and pulmonary arterial hypertension [21, 29].

RDW values were higher in the exitus group than in the survivors, and RDW was also found to be an independent risk factor for mortality. Increased RDW was linked to all-cause mortality in another study [10]. Fibrotic lung diseases cause chronic hypoxemia and tissue hypoxia, leading to an increase in EPO secretion. Tissue hypoxia provokes an inflammatory response and oxidative stress, both of which may disrupt erythrocyte turnover and may lead to anisocytosis and increased RDW levels. As the severity of lung disease increases, the RDW level may increase, suggesting that RDW can be used as a predictor of disease severity and mortality.

There are a few limitations to our study, the first of which is its retrospective design. A further limitation is that the study patients were not classified with CT staging systems based on the predominant lesion type, and the intensity of the reticular pattern or emphysema, which may have affected the results of the study. Also, the use of the helium dilution technique for the measurement of lung volume may underestimate absolute lung volumes, especially in patients with CPFE.

\section{Conclusion}

The RDW test is a readily available, convenient, and inexpensive prognostic indicator of various diseases. High RDW values would appear to be a simple prognostic factor in patients with IPF or CPFE. Further studies evaluating the usefulness of RDW values associated with IPF and CPFE are encouraged to elucidate the mechanisms.

\section{Statement of Ethics}

This study was approved by the Atatürk Chest Diseases and Chest Surgery Education and Research Hospital Ethics Committee. All procedures performed in the studies involving human participants were carried out in accordance with the ethical standards of the institutional and/or national research committee, and with the 1964 Helsinki Declaration and its later amendments or comparable ethical standards.

\section{Conflict of Interest Statement}

All of the authors declare no conflict of interest.

\section{Author Contributions}

Conception and design: A.G.K., B.A.Ö., T.Ş.Ö., M.Ö., and Y.E.; data collection: A.G.K., B.A.Ö., T.Ş.Ö., and M.Ö.; data analysis: A.G.K.; literature review: A.G.K., B.A.Ö., T.Ş.Ö., M.Ö., and Y.E.; writing: A.G.K., B.A.Ö., T.Ş.Ö., M.Ö., and Y.E.; and critical review: A.G.K., B.A.Ö., T.Ş.Ö., M.Ö., and Y.E. 


\section{References}

1 Simel DL, DeLong ER, Feussner JR, Weinberg JB, Crawford J. Erythrocyte anisocytosis. Visual inspection of blood films vs automated analysis of red blood cell distribution width. Arch Intern Med. 1988;148(4):822-4.

2 Ichinose J, Murakawa T, Kawashima M, Nagayama K, Nitadori JI, Anraku M, et al. Prognostic significance of red cell distribution width in elderly patients undergoing resection for non-small cell lung cancer. J Thorac Dis. 2016;8(12):3658-66.

3 Schepens T, De Dooy J, Verbrugghe W, Jorens PG. Red cell distribution width (RDW) as a biomarker for respiratory failure in a pediatric ICU. J Inflamm. 2017;14:12.

4 Zhou XY, Chen HL, Ni SS. Red cell distribution width in predicting 30 -day mortality in patients with pulmonary embolism. J Crit Care. 2017;37:197-201.

5 Perlstein TS, Weuve J, Pfeffer MA, Beckman JA. Red blood cell distribution width and mortality risk in a community-based prospective cohort. Arch Intern Med. 2009;169(6): 588-94.

6 Raghu G, Collard HR, Egan JJ, Martinez FJ, Behr J, Brown KK, et al. An official ATS/ERS/ JRS/ALAT statement: idiopathic pulmonary fibrosis: evidence-based guidelines for diagnosis and management. Am J Respir Crit Care Med. 2011;183(6):788-824.

7 Jankowich MD, Rounds SIS. Combined pulmonary fibrosis and emphysema syndrome: a review. Chest. 2012;141(1):222-31.

8 Cottin V, Nunes H, Brillet PY, Delaval P, Devouassoux G, Tillie-Leblond I, et al. Combined pulmonary fibrosis and emphysema: a distinct underrecognised entity. Eur Respir J. 2005;26(4):586-93.

9 Puglisi S, Torrisi SE, Vindigni V, Giuliano R, Palmucci S, Mulè M, et al. New perspectives on management of idiopathic pulmonary fibrosis. Ther Adv Chronic Dis. 2016;7(2):10820.

10 Nathan SD, Reffett T, Brown AW, Fischer CP Shlobin OA, Ahmad S, et al. The red cell distribution width as a prognostic indicator in idiopathic pulmonary fibrosis. Chest. 2013; 143(6):1692-8

11 Harari S, Elia D, Humbert M. Pulmonary hypertension in parenchymal lung diseases: any future for new therapies? Chest. 2018;153(1): $217-23$.

12 Tomassetti S, Ryu JH, Poletti V. Staging systems and disease severity assessment in interstitial lung diseases. Curr Opin Pulm Med. 2015;21(5):463-9.

13 Su C, Liao LZ, Song Y, Xu ZW, Mei WY. The role of red blood cell distribution width in mortality and cardiovascular risk among patients with coronary artery diseases: a systematic review and meta-analysis. J Thorac Dis. 2014;6(10):1429-40.

14 Montagnana M, Danese E. Red cell distribution width and cancer. Ann Transl Med. 2016; 4(20):399.

15 Kos M, Hocazade C, Kos FT, Uncu D, Karakas E, Dogan M, et al. Evaluation of the effects of red blood cell distribution width on survival in lung cancer patients. Contemp Oncol. 2016;20(2):153-7.

16 Anwar A, Ruffenach G, Mahajan A, Eghbali M, Umar S. Novel biomarkers for pulmonary arterial hypertension. Respir Res. 2016;17(1): 88.

17 Dias OM, Baldi BG, Costa AN, Carvalho CR. Combined pulmonary fibrosis and emphysema: an increasingly recognized condition. J Bras Pneumol. 2014;40(3):304-12.

18 Kwiatkowska S. IPF and CPFE - the two different entities or two different presentations of the same disease? Adv Respir Med. 2018; 86(1):23-6.

19 Ryerson CJ, Hartman T, Elicker BM, Ley B, Lee JS, Abbritti M, et al. Clinical features and outcomes in combined pulmonary fibrosis and emphysema in idiopathic pulmonary fibrosis. Chest. 2013;144(1):234-40.

20 Skjorten I, Hilde JM, Melsom MN, Hansteen V, Steine K, Humerfelt S. Pulmonary artery pressure and $\mathrm{PaO} 2$ in chronic obstructive pulmonary disease. Respir Med. 2013;107(8): 1271-9.
21 Tertemiz KC, Ozgen Alpaydin A, Sevinc C, Ellidokuz H, Acara AC, Cimrin A. Could "red cell distribution width" predict COPD severity? Rev Port Pneumol. 2016;22(4):196-201.

22 Ycas JW, Horrow JC, Horne BD. Persistent increase in red cell size distribution width after acute diseases: a biomarker of hypoxemia? Clin Chim Acta. 2015;448:107-17.

23 Rhodes CJ, Wharton J, Howard LS, Gibbs JS, Wilkins MR. Red cell distribution width outperforms other potential circulating biomarkers in predicting survival in idiopathic pulmonary arterial hypertension. Heart. 2011;97(13):1054-60.

24 Alattar FT, Imran NB, Patel P, Usmani S, Shamoon FE. Red cell distribution width (RDW) correlates with markers of diastolic dysfunction in patients with impaired left ventricular systolic function. Int J Cardiol Heart Vasc. 2016;10:13-6.

25 Nathan SD, Shlobin OA, Ahmad S, Urbanek S, Barnett SD. Pulmonary hypertension and pulmonary function testing in idiopathic pulmonary fibrosis. Chest. 2007;131(3):657-63.

26 Zairova AR, Oshchepkova EV, Rogoza AN. [Vasomotor endothelial dysfunction in young men with grade 1 arterial hypertension]. Kardiologiia. 2013;53(7):24-30.

27 Solak Y, Yilmaz MI, Saglam M, Caglar K, Verim S, Unal HU, et al. Red cell distribution width is independently related to endothelial dysfunction in patients with chronic kidney disease. Am J Med Sci. 2014;347(2):118-24.

28 Farkas N, Szabó A, Lóránd V, Sarlós DP, Minier T, Prohászka Z, et al. Clinical usefulness of measuring red blood cell distribution width in patients with systemic sclerosis. Rheumatology. 2014;53(8):1439-45.

29 Smukowska-Gorynia A, Tomaszewska I, Malaczynska-Rajpold K, Marcinkowska J, Komosa A, Janus M, et al. Red blood cells distribution width as a potential prognostic biomarker in patients with pulmonary arterial hypertension and chronic thromboembolic pulmonary hypertension. Heart Lung Circ. 2018;27(7):842-8. 